Between "letras \& armas", History as Dispute. Considerations on LusoBrazilian Historiography in the $18^{\text {th }}$ century

\title{
Entre "letras \& armas", a história como disputa. Considerações sobre a historiografia luso-brasileira no século XVIII'
}

\section{Fernando Nicolazzi}

Doutor em História pela

Universidade Federal do Rio Grande

do Sul (UFRGS) e Professor no

Departamento de História da

Universidade Federal de Ouro Preto

(ICHS / UFOP - Mariana / Brasil)

e-mail:f.nicolazzi@hotmail.com

\section{Resumo}

Este ensaio elabora algumas considerações sobre a prática historiográfica no contexto luso-brasileiro do século XVIII. Partindo do topos "letras $\&$ armas", recorrente em tal ambiente intelectual para se definir as relações entre saber e poder, mundo letrado e espaço político, sugere-se que a dissertação histórica, tal como empreendida por alguns autores portugueses e "brasílicos", sobretudo no âmbito da Academia Brasílica dos Esquecidos (1724), operava como modalidade privilegiada de discurso para definição de uma legitimidade para a escrita da história, situando-se entre a feitura de memórias particulares e a história propriamente dita.

\begin{abstract}
This essay traces some considerations on the 18th century Luso-Brazilian historiographical practice. From the topos "letras \& armas" - common in that intellectual ambiance to define the relations between knowledge and power, literary world and political space - it is suggested that the historical dissertation was a privileged discursive modality for the definition of the legitimacy of the historical writing. Therefore, the dissertation was located between the mode of making particular memories and history itself. The "armas \& letras" topic is confronted in some Portuguese and "Brasilic" authors, above all in the Academia Brasílica dos Esquecidos (1724).
\end{abstract}

\section{Palavras-chave}

América portuguesa / Brasil, memórias históricas, historiografia

\section{Keywords}

Portuguese America / Brazil, historical memoirs, historiography
1

Manifesto minha gratidão a Taise Quadros da Silva, por ter lido e comentado este texto, indicado obras importantes para este estudo (como as de João Pedro Ribeiro) e por ter me dado a oportunidade do diálogo sobre o século XVIII. Agradeço ainda aos participantes do simpósio temático Historiografia e Escrita da História: as Dimensões Éticas do Ofício do Historiador, que discutiram uma versão preliminar deste artigo, durante o XXV Simpósio Nacional de História, ocorrido em Fortaleza (Julho/2009). 
Na tarde de sete de março de 1724, o vice-rei do Estado do Brasil, senhor Vasco Fernandes César de Meneses, diante de alguns letrados de Salvador, fez conhecer seus anseios por se fundar nesta cidade uma agremiação literária para que os talentos que ali floresciam pudessem sair da bruma espessa do desconhecimento que os encobria. Desta feita, cumpriria, assim, sua "profissão de ilustrar as armas" e sua "propensão a honrar as letras" daquela vasta província do Império lusitano, conforme palavras que mais tarde foram-Ihes dirigidas. Os sete convidados que ouviram do vice-rei tal demanda, de pronto e bom grado se puseram a dar cabo a tal empreendimento. Eram eles o reverendo padre Gonçalo Soares de França, os desembargadores Caetano de Brito Figueiredo e Luís de Siqueira da Gama, o juiz de fora Inácio Barbosa Machado, o coronel Sebastião da Rocha Pita, o capitão João de Brito Lima e, por fim, José da Cunha Cardoso. Eis que, "filha de tão excelente e generoso espírito", nascia sob a divisa sol oriens in occiduo a Academia Brasilica dos Esquecidos. Conforme a decisão prévia dos sete ilustres fundadores, ela teria por matéria principal de seus estudos a "história brasílica", compreendida em quatro partes principais: a história natural, a militar, a eclesiástica e, finalmente, a história política. ${ }^{2}$

Cerca de um mês e meio após a fundação, os membros da associação

Academia Brasilica dos Esquecidos. Notícia da fundação. In: CASTELLO, José Aderaldo. 0 movimento academicista no Brasil, 1641-182022. Vol.1, T.1. São Paulo: Conselho Estadual da Cultura, 1969. p.3 e p.4 (todas as citações deste trabalho procuram respeitar a sintaxe e a ortografia da fonte consultada).

3

CARDOSO, José da Cunha. Oração, com que na dominica in Albis e vinte, e três de abril dêste ano de 1724 abriu a Academia Brasilia o Doutor José da Cunha Cardoso. In: CASTELLO, José Aderaldo. Op.Cit. p.9.

4

Ibidem. p.11

5

KANTOR, Iris. Esquecidos e Renascidos. Historiografia acadêmica luso-brasileira (17241759). São Paulo: Hucitec; Salvador: Centro de Estudos Baianos/UFBA, 2004. p.16.

\section{6}

Ainda sobre este assunto, particularmente sobre a noção territorial contida na Historia da America Portugueza, desde o anno de mil e quinhentos do seu descobrimento, até o de mil setecentos e vinte e quatro, publicada em 1730 pelo ex-acadêmico Sebastião da Rocha Pitta, remeto a ANDREAZZA, Maria Luiza. Dominum, terras e vassalagem na América portuguesa de Sebastião da Rocha Pitta. Comunicação apresentada no Seminário Facetas do Império na História, Programa de Pós-Graduação em História da Universidade Federal do Paraná, 6-10 de novembro de 2006. se reuniram para iniciar os trabalhos da sua primeira reunião. Na oração proferida nesta oportunidade, o acadêmico José da Cunha Cardoso, de codinome Venturoso, expôs com tintas vistosas os desígnios principais da desejada Academia que, não obstante, teria vida demasiado breve, findando seus trabalhos menos de um ano após seu início. Para ele, tratava-se naquele momento do traslado da mais célebre cidade grega para a melhor cidade da América, fundando-se ali, em Salvador, um novo Ateneu, que era como a aparição do sol nas terras americanas. Nas suas palavras, "agora sairão à luz os que o nosso descuido cobria com as sombras do esquecimento, que por isso tão entendidos, como modestos se apropriaram do título dos Esquecidos". 3 A academia, pensada como um "teatro da erudição", colocava-se diretamente vinculada aos objetivos do império maritimo português, ressaltando desde logo as razões inerentes para tanto, afinal "armas e letras são filhas de um mesmo parto, ou partes de um mesmo corpo: conselhos e forças, olhos e mãos". Nesse sentido, "toda se equivoca a campanha literária com a república militar". 4 A escolha dos termos é significativa desta simbiose, uma vez que nossos ouvidos estão hoje mais afeiçoados a ouvir falar em repúblicas de letras e campanhas militares. Topos antigo na tradição ibérica, letras e armas são termos que se coadunavam para estabelecer as relações entre pretensões políticas e intenções literárias. De todo modo, há nessas palavras indícios claros dos contornos que uma possivel história brasílica teria ao ser produzida naquela academia. Segundo Iris Kantor, "ao longo da primeira metade do século XVIII, o movimento academicista ajudou a desencadear uma nova percepção sobre o estatuto político do território colonial, estimulando, assim, a reflexão sobre a natureza dos laços que prendiam a América ao Reino: amarras simultaneamente jurídicas, familiares, linguísticas, econômicas e culturais". 50 discurso sobre a história e a reflexão sobre 0 passado americano seriam, por conseguinte, elementos decisivos para a "percepção dos vínculos entre Colônia e Metrópole" e, por extensão, para a própria definição dos significados do império português; armas e letras operando conjuntamente para a sustentação dos domínios imperiais. ${ }^{6}$ 
Sobre o tema, remeto para o trabalho seminal de CURTIUS, Ernst Robert. Literatura européia e Idade Média latina. Brasilia: INL, 1979. p.174187.

0 texto destas dissertações foi publicado modernamente por José Aderaldo Castello, na obra 0 movimento academicista no Brasil, 1641 1820-22. Vol.I, T.5. São Paulo: Conselho Estadual da Cultura, 1969, com base nos manuscritos depositados no Mosteiro de Alcobaça em 1761. Apenas após ter findado este artigo, tive acesso a uma quarta dissertação não publicada na coletânea mencionada, embora tenha sido anunciada desde a fundação da Academia. Trata-se da "Dissertação da História Militar do Brasil", elaborada pelo sócio Inácio Barbosa Machado, que não foi levada em consideração nos argumentos aqui desenvolvidos. Agradeço a Pedro Telles da Silveira por ter me disponibilizado o texto.

BLUTEAU, Raphael. Vocabulario portuguez e latino. T.1. Coimbra: Collegio das Artes da Companhia de Jesus; Lisboa: Joseph Antonio da Silva, 1712. p.287.
0 topos de longa data que sugere a relação íntima entre "letras \& armas", estabelece certa reciprocidade a partir da qual linguagem e experiência, palavra e ação, ciência e política misturam-se de modo que a tarefa do literato e aquela do militar podem ser equiparadas segundo princípios equivalentes. ${ }^{7}$ Ou seja, o glorioso empreendimento lusitano se deu com homens que carregavam, muitas vezes simultaneamente, a pena e a espada. A Academia dos Esquecidos nasce sob o signo dessa relação. 0 que está por trás dessa questão é justamente o papel do discurso histórico como elemento fundamental da política imperial portuguesa, encarado segundo uma perspectiva de historia magistra vitae em suas relações com as práticas do bom governo. Como afirmou retoricamente um dos acadêmicos, "nada nos persuade mais, dizem os retóricos do que são os exemplos, e as autoridades; e para os politicos persuadirem aos príncipes, aos Reis, aos Monarcas, aos Imperadores, o bom govêrno, e o bem comum, que melhores exemplos, que mais sentenciosas autoridades podiam ter do que os testificados nas histórias, e as escritas pelos sábios historiadores".

Se, portanto, o tema "letras \& armas" permite compreender a história do império lusitano, ela igualmente possibilita a compreensão da historiografia, ou pelo menos de parte da historiografia que era produzida dentro do espaço imperial. No caso dos acadêmicos brasilicos da primeira metade do século XVIII, a produção historiográfica se manifesta, entre outras formas, na elaboração de dissertações históricas sobre assuntos específicos. Nestes textos, evidencia-se um tom combativo pelo qual se disputam versões distintas sobre fatos relativos à história brasilica. A atenção a três dessas dissertações pode lançar luz à compreensão das modalidades de prática historiográfica disponiveis para os homens de letras setecentistas na América portuguesa. Neste trabalho, tomo como objeto de estudo as dissertações da história política, natural e eclesiástica lidas respectivamente pelos acadêmicos Luís de Siqueira da Gama, de codinome Ocupado, Caetano de Brito Figueiredo, o Nubiloso e, por fim, o padre Gonçalo Soares de França, conhecido nos certames literários como Obsequioso. ${ }^{8} \mathrm{~A}$ hipótese que orienta a leitura sugere que é possivel considerar estes textos como indícios plausiveis de uma preocupação erudita com a prática da investigação que perpassa a escrita da história brasilica no século XVIII. Uma investigação, cabe dizer, de matizes bastante particulares, mas por meio da qual intentava-se separar o verdadeiro do falso, a versão histórica pertinente aos fatos narrados da versão equivocada e não fundamentada sobre os mesmos fatos.

\section{II}

Luis de Siqueira da Gama, nas suas "Dissertações altercadas, e resolutas, para melhor averiguação da verdade na história do Brasil", desde o título, já fornece pistas para se pensar o estatuto epistemológico do gênero dissertativo na primeira metade do setecentos. Considerando o significado do verbo "altercar", tem-se, segundo o Vocabulario portuguez e latino de Raphael Bluteau, "disputar. Contender alternadamente". 9 "Altercadas", termo reforçado por "resolutas", portanto, traz o sentido de que o que ali se apresentam já são disputas resolvidas, ou seja, o resultado de um confronto já ocorrido. Todavia, na primeira das dez dissertações de história política apresentadas pelo lente Ocupado, em uma espécie de preâmbulo no qual se definem pormenorizadamente o que ele entende por política, história, Brasil e dissertação, esta é ali definida da seguinte forma: 
10

GAMA, Luis de Siqueira da. Dissertações altercadas, e resolutas, para melhor averiguação da verdade na história do Brasil. In: CASTELLO, José Aderaldo. 0 movimento academicista no Brasil, 1641-1820-22. Vol.1, T.5. São Paulo: Conselho Estadual da Cultura, 1969. p.13.

11

Ibidem. p.21.

12

Ibidem. p.24.
Dissertação se diz tôda aquela disputa que se controverte com palavras a fim de se exprimir clara e especialmente a sentença melhor, em qualquer questão: deduz a sua etimologia do freqüentativo disserto dis sertas (de quem é nome derivado) e significa disputar ou declarar com palavras; êste val o mesmo que o verbo dissero, que segundo o Léxico de Uveterano, quer dizer; e exprimir clara e especialmente a sentença de cada um. ${ }^{10}$

A origem desta forma de disputa, segundo Siqueira da Gama, remontaria às "primeiras mantilhas do universo", logo em seguida ao ato criador realizado por Deus. 0 acadêmico sugere que a primeirissima dissertação ocorrida foi aquela travada entre Eva, consorte do primeiro homem e "nossa primeira mãe", e a astuciosa e fatal serpente. 0 desfecho desta disputa é por todos conhecido. Característica fundamental das dissertações, portanto, é o fato da disputa se desenrolar através de palavras, o que a distingue, por exemplo, dos jogos e das batalhas.

Mais adiante no texto, após ter sugerido a divisão do gênero histórico em dois tipos principais, a história "rigorosa" e a "menos rigorosa", considerando que "a rigorosa é a verdadeira história, a menos rigorosa é a fingida ou intelectual",11 Luis de Siqueira da Gama complementa ainda de forma mais evidente sobre o caráter disputável das dissertações, atribuindo a elas regras relativamente bem precisas, segundo o decoro esperado para o gênero:

Tem por matéria a dissertação, tôda a que foi ou possa ser disputável, por objeto, tem a opinião melhor, para fim de averigüação da verdade: para conhecimento da que se propõem as dúvidas, se consideram as respostas, se formam as instâncias, e discorrem as distensões; devem porém os argumentos serem moderados porquanto se a dissertação for nímia imoderadamente ou por capricho, ou por vaidade, ou por espírito de contradição, tão longe está de ser semelhante controvérsia afeto louvável, exercício virtuoso ou empenho científico, que necessariamente há de produzir efeitos contrários, e a dissertação que sòmente se devia alterar a fim de conhecer a verdade e concluir a sentença melhor; se controverter nimiamente imoderada, é preciso que se há de perturbar o certo, escurecer o claro, e confundir-se totalmente a melhor opinião. ${ }^{12}$

0 autor das "Dissertações Acadêmicas, e Históricas, nas quais se trata da História natural das Coisas do Brasil", Caetano de Brito e Figueiredo, por sua vez, acrescenta dados distintos à questão. Para o desembargador, há particularidades que caracterizam o aporte historiográfico.

Não confundiremos com têrmos Escolásticos o estilo Acadêmico; porque suposto escrevemos Dissertações estas se animam com o caráter da História, donde só com o expressivo da narração, e não com o rigor da disputa deve declarar-se 0 duvidoso, e concluir-se o verdadeiro, ou o verossimel [sic]. ${ }^{13}$

Figueiredo estabelece uma distinção entre o campo historiográfico, propriamente narrativo, e aquele das disputas religiosas marcadas pela tradição escolástica, cujo problema seria, ao que parece, causar o fastio dos ouvintes. As referências indicadas na sequência são dignas de nota. Para estabelecer o seu cânone particular dos autores versados nas regras da boa história, Figueiredo começa por citar Dionisio Lambino, nome aportuguesado para o erudito francês do século XVI, Denis Lambin, professor de latim e grego no Collège de France, tradutor de Aristóteles e responsável por edições de autores como Horácio e Cícero. Dele, Caetano de Brito ressalta a diferença entre filósofos e historiadores, ainda que 
14

Sobre as dissertações de Caetano de Brito e Figueiredo, ver PEDROSA, Fábio Mendonça. A Academia Brasília dos Esquecidos e a história natural da Nova Lusitânia. Revista da SBHC, n.1, 2003. p.21-28

\section{5}

Para um estudo que discute a relação antigos/ modernos na historiografia luso-brasileira da primeira metade do século XVIII, ver KANTOR, Iris. Antigos e modernos na historiografia acadêmica portuguesa e brasilica. Cronografias e representação do passado. In: PIRES, Francisco Murari (org.). Antigos e modernos. Diálogos sobre a (escrita da) história. São Paulo: Alameda, 2009.

\section{6}

FRANÇA, Gonçalo Soares de. Dissertações da história eclesiástica do Brasil. In: CASTELLO, José Aderaldo. 0 movimento academicista no Brasil, 1641-1820-22, Vol.1, T.5. São Paulo: Conselho Estadual da Cultura, 1969. p.225.

17

GAMA, Luis de Siqueira da. Dissertações altercadas, e resolutas, para melhor averiguação da verdade na história do Brasil. In: CASTELLO, José Aderaldo. Op.Cit. p.12. não desenvolva o argumento. Além de Lambin, nomes como Luciano de Samósata, autor de texto grego do século II d.C. sobre a escrita da história, versado para o latim com Quomodo historia conscribenda, e Jean Bodin, que em 1566 publica seu Methodus ad facilem historiarum cognitionem, figuram na lista daqueles que "trataram do Método, com que deve compor-se a história".14

Já o padre Gonçalo Soares de França, ocupado com as "Dissertações da história eclesiástica do Brasil", no antilóquio das dissertações, oferece ainda uma outra postura para o desenvolvimento desta reflexão. 0 religioso se considera instruido nas regras adequadas que uma história bem elaborada exige de seu praticante. São mencionados os antecedentes que o orientaram, entre os quais Heródoto, Polibio, Flávio Josefo, Tito Lívio, Tácito, entre os antigos e, dos modernos, são mencionados, entre outros, Guicciardini e João de Barros..$^{15}$ Contudo, fazendo menção direta às conferências já realizadas, sobretudo as de história natural e política, o padre e acadêmico Obsequioso informa seus interlocutores que não realizará ali uma história uma vez que, nas suas palavras, "mais havemos de descrever umas dissertações históricas, que uma história já disputada (porque dos propriamente historiadores é só obrigação narrar, e apenas refletir, sem a pensão de questionar) e assim variei de sistema e mudei de bastidor, trocando o estilo, e alterando a frase".16 Aqui, percebe-se o lugar ocupado pela dissertação na economia geral do trabalho historiográfico: ela é ainda o texto sobre um objeto em disputa, etapa fundamental para a narrativa propriamente histórica e, como tal, demanda procedimentos distintos de escrita (outro "sistema", outro "bastidor").

Às formulações acima definidas pelos três acadêmicos, vêm se complementar as idéias por eles elaboradas a respeito dos significados específicos da história. Para Siqueira da Gama, enquanto "razão das coisas passadas", a história se distingue no plano formal tanto da oratória quanto da poesia.

\footnotetext{
[a história] define-se verdadeira narração das coisas passadas, decorosamente referidas, segundo a série dos tempos em que sucederam: a partícula narração é gênero, transcendental para a oratória, e para a poesia; porque ambas estas científicas artes, se valem também da narração: a oratória para persuadir o útil, e honesto, o provável [.] a Poesia para cantar o deleitável, e o verossímil, as mais partículas são diferença; porquanto a História escreve as coisas que sucederam realmente, como se obraram, segundo a série, e ordem dos tempos em que aconteceram: a oratória sim refere as coisas como aconteceram, mas não as relata tão estreita, e rigorosamente: porque pode antepor, ou pospor os sucessos, conforme ao melhor arbitrio do orador: a poesia expõe seus argumentos não como foram verdadeiramente sucedidos, mas sim como deviam ser obrados, e para êste fim tem o Poeta jurisdição de inventar, fingir, diminuir, ou acrescentar tudo quanto melhor lhe parecer. ${ }^{17}$
}

Se, portanto, os três gêneros de discurso se valem formalmente da narrativa, a função e as possibilidades de cada um deles podem ser nitidamente discerniveis: a oratória persuade por meio do que é provável, visando a utilidade do discurso; a poesia, voltada ao verossímil, procura causar prazer; já a história, esta fica restrita ao âmbito factual, às "coisas que sucederam realmente", respeitando a ordem cronológica do ocorrido. Nesse sentido, ela se difere da primeira na medida em que a obediência à cronologia não é para esta condição fundamental, e se distingue da segunda, uma vez que a esta é permitida a fabulação. 
"Dissertarei; por se altercar com grande dúvida, se a descrição das coisas naturais se deve chamar história; porquanto suposto Plínio the impusesse êste majestoso nome, e o seguissem outros; contudo o Príncipe da eloqüência Romana só a denominou por memória pública de todos os Segredos, e por monumento dos tempos, dos lugares, dos homens, e das coisas". FIGUEIREDO, Caetano de Brito e. Dissertações Acadêmicas, e Históricas, nas quais se trata da História natural das Coisas do Brasil. In: CASTELLO, José Aderaldo. 0 movimento academicista no Brasil, 1641-1820-22. São Paulo: Conselho Estadual da Cultura, 1969. p.146. Ver ainda [VOLTAIRE]. Histoire. In: Encyclopédie, ou dictionnaire raisonné des sciences, des arts et des métiers, par une societé de gens de lettres. Tome VIII. Neufchastel, 1755.

\section{9}

FRANÇA, Gonçalo Soares de. Dissertações da história eclesiástica do Brasil. In: CASTELLO, José Aderaldo. Op.Cit. p.229.
20

BLUTEAU, Raphael. Vocabulario portuguez e latino. T.3. Coimbra: Collegio das Artes da Companhia de Jesus; Lisboa: Joseph Antonio da Silva, 1713. p.322 e 250, respectivamente.
Se Caetano de Brito não chega a se deter com mais vagar nas definições precisas da história, limitando-se a indagar, como Voltaire fará de forma mais decisiva algumas décadas depois, se a história natural pode ser, de fato, considerada história, ${ }^{18}$ o padre Soares de França apresenta considerações importantes. Para o clérigo, a história demanda uma forma bastante particular, a qual parece obedecer a regras muito precisas:

\section{[...] como não há matéria sem forma, terá esta forma a mesma matéria. Nas matérias controversas, primeiro proporei as opiniões contrárias, ou as razões opostas, e depois estabelecerei as próprias conclusões: nos sucessos liquidos só se ouvirá a narração: o estilo variará ao compasso dos assuntos; o narrativo para referir, o oratório para falar, o altiloquo para descrever. 0 primeiro será chão, e cheio, com palavras mais significativas, que pomposas, porque sempre tive por inúteis as que superabundam a expressão do conceito; o segundo mais ativo, ou com expressões mais vivas, como para persuadir; o último mais levantado, ou com visos de poético (dentro porém da sua esfera) como quem pinta, porque se a pintura é como a poesia [...] pelo que retrata, porque não será a perspectiva histórica como a poética, pelo que expressa? ${ }^{19}$}

Para Soares de França, há uma distinção formal entre o discurso a ser disputado e aquele cujos sucessos são já "líquidos". Neste caso, o formato narrativo é aquele que melhor se adapta à tarefa, cuja intenção é simplesmente referir algo e que, por isso, necessita apenas de palavras "significativas", desprovidas de floreios e pompas; já para o primeiro caso, onde a intenção é persuadir o interlocutor da validade de uma proposição em relação à outra em contrário, demanda-se maior capacidade argumentativa e, portanto, maior poder oratório. Ou seja, entre narração e dissertação, segundo as formulações do acadêmico, há uma distinção não apenas formal como qualitativa, pois como havia sido colocado anteriormente, ao historiador cabe apenas narrar e não questionar, o questionamento devendo ocorrer justamente no âmbito da dissertação.

Em resumo, constatam-se dois procedimentos correlatos na tarefa "historiográfica" do letrado brasílico ligado à Academia dos Esquecidos, os quais são definidos segundo seus aspectos formais, mas também a partir da sua posição na elaboração do saber histórico. Se a narrativa histórica, etapa final do trabalho historiográfico, se distingue tanto da retórica quanto da poética pelo seu decoro e pela intenção de verdade que carrega, a dissertação histórica, por sua vez, se situa em uma etapa anterior, particularmente enquanto procedimento de produção da verdade sobre temas ainda em disputa e que, dessa maneira, vincula-se diretamente ao campo da retórica e da persuasão.

\section{III}

Do que foi considerado até aqui, resta definir com mais precisão o que significa de fato o mecanismo dissertativo utilizado pelos acadêmicos Esquecidos. Segundo o vocabulário de Raphael Bluteau, o termo dissertação diz respeito ao "discurso, ou tratado scientífico sobre alguma matéria, ou questão", fazendo referência ao termo latino "dissertatio". Por sua vez, na mesma obra a palavra disputa aparece dicionarizada como "contenda por palavras, ou por escrituras, com que se prova alguma cousa, ou se refutão as razoens em contrario". 0 fato relevante desta denotação está justamente nas referências latinas acrescidas, "disputatio" e "dissertatio".20 Passado um século, na edição de 1813 do dicionário de Antonio de Moraes 


\section{1}

SILVA, Antonio de Moraes. Diccionario da lingua portugueza, T.1. Lisboa: Typographia Lacerdina, 1813. p.626.

\section{2}

No seu De oratore, ao estipular as cinco partes da arte retórica, Cícero coloca na boca de Crassus algumas palavras significativas. Afinal, como sugere o reitor, "o primeiro dever do orador é de arranjar-se para convencer". Deste modo, após o orador 1) encontrar as idéias, 2) organizá-las judiciosamente, 3 ) revesti-las com a expressão adequada, 4) fixá-las na memória e, enfim, 5) debitá-las com dignidade e graça, após o cumprimento de todas estas etapas, então, supõe-se convencido ou persuadido o seu interlocutor. Crassus assim resume a tarefa: "antes de abordar o objeto, era necessário conciliar o espírito dos auditores, depois expor o assunto, indicar o ponto em discussão, dar as provas como apoio da tese, refutar as objeções e, ao final, amplificar e desenvolver tudo aquilo que está em nosso favor, enfraquecer e arruinar tudo o que a parte contrária defende". CICERO. De oratore, I, XXXI. Utilizei a edição francesa estabelecida, traduzida e anotada por François Richard, CICÉRON. De l'orateur. Paris: Garnier, 1932.

\section{3}

ALMEIDA, Diogo Fernandes de. Dissertação historica, jurídica, e apologetca, que na Conferencia da Academia Real da Historia Portugueza de 14. de Fevereiro de 1732. leu D. Diogo Fernandes de Almeida, em defeza da Conta, que deu dos seus estudos no felicíssimo dia de 7. e Setembro de 1731. Lisboa Occidental : na officina de Joseph Antonio da Silva, Impressor da Academia Real, M. DCC. XXXII [1732], p. 2.

\section{4}

Reflexoens sobre o estudo academico. In: Collecçam dos documentos, estatutos, e memorias da Academia Real da Historia Portugueza, que neste anno de 1721, se compuzerão, e se imprimirão por ordem dos seus censores, dedicada a El Rey Nosso Senhor, Seu Augustissimo Protector, e ordenada pelo Conde de Villamayor, secretario da mesma Academia. Lisboa Occidental: na Oficina de Pascoal da Sylva, impressor de S. Magestade Real. MDCCXXI [1721]. Agradeço a Taise Quadros da Silva por ter disponibilizado o texto.
Silva, ambos os termos sofrem variações mínimas para as intenções deste trabalho, mas ainda assim importantes. Dissertação se refere ao "discurso didactico sobre algum ponto litterario, ou scientifico", enquanto que disputa permanece significando uma "contenda, controversia vocal, ou por escrito", o que remonta à ação de "controverter, mover questão sobre a certeza, ou falsidade, bondade, ou maldade". Aquilo que é disputado trata-se de um "averiguado caso". 21

A idéia de disputa, nesse sentido, pode ser pensada enquanto um procedimento discursivo e retórico utilizado para o estabelecimento de uma verdade, a partir da refutação direta da sua parte contrária. 22 A diferença que sobressai entre as definições dadas por Bluteau e por Moraes Silva é o fato de que, para o primeiro, a disputa prova alguma coisa, ao passo que isso não se mostra tão evidente para o segundo. Ou seja, a disputa em si funciona como razão suficiente para a definição do recorte entre o verdadeiro e sua contraparte. Em certa medida, tomando-se as dissertações históricas dos autores brasílicos da Academia dos Esquecidos, pode ser sugerido que tal gênero discursivo funciona de forma importante dentro dos procedimentos elaborados para a definição dos critérios da investigação histórica praticada por aqueles letrados. As dissertações seriam, por conseguinte, uma etapa fundamental que ofereceria os elementos principais para uma escrita verdadeira da história.

Dois outros exemplos ilustram ainda este teor comprobatório que a idéia de dissertação terá entre a primeira metade do século XVIII e a primeira metade do XIX. Em 1732, D. Diogo Fernandes de Almeida, membro desde 1727, lê diante dos seus pares na Academia Real da História Portuguesa, uma "Dissertação historica, jurídica, e apologetica", na qual defende-se dos ataques dirigidos por outros letrados sobre sua história da fundação do Collegio de São Pedro de Coimbra no século XVI. Os termos são claros e apontam um teor nítido de disputa:

Não cuidey ao principio, que me fosse preciso em materia taõ clara tratar como ponto duvidoso aquillo, que estava tanto à luz do dia, e entrar na animosa contestação de huma doutrina de tão pouca importancia; mas como houve alguns generosos Athletas, que só por exercitarem as suas forças, a sua grande destreza, e agilidade, estimaraõ ter contendor para brilhar nesta área, não he justo que tendo eu sahido primeiro a campo, Ihes ceda desde logo a vitória. 23

A posição de Fernandes de Almeida coaduna-se com as propostas metódicas definidas pelos fundadores da Academia Real, quando se propõem a definir o estatuto do estudo acadêmico. Nas Reflexoens sobre o estudo academico, consta uma sugestão importante que deve orientar os letrados nas feituras de suas histórias:

...e como ha de tratar com dissertações tudo o que tiver questaõ na antiguidade, na Chronologia, e nas mais materias duvidosas, citará fielmente nas margens os Authores, que segue com o numero dos livros, e capitulos, e ainda das folhas declarando a impressão que segue; naõ só dos impressos fará esta memoria, mas tambem allegará os manuscritos, e as Livrarias em que existem, para que tambem se dê o justo agradecimento a quem os participou. 24

Já a partir de 1810, o sócio da Academia Real das Ciências de Lisboa e primeiro lente de diplomática na Universidade de Coimbra, João Pedro Ribeiro, começa a publicar sob os auspícios daquela mesma instituição algumas "Dissertações chronologicas e criticas" sobre diversos aspectos 
da história portuguesa. 0 breve prólogo que abre o primeiro tomo das publicações deixa transparecer o intuito da obra:

\section{5}

RIBEIRO, João Pedro. Dissertações chronologicas e criticas sobre a historia e jurisprudência ecclesiastica e civil de Portugal publicadas por ordem da Academia R. das Sciencias de Lisboa pelo sócio João Pedro Ribeiro, 5 tomos. Lisboa: na Typografia da mesma Academia, 1810-1836 (a citação consta no prólogo do tomo I).

\section{6}

Como se sabe, a partir do que chamou de "lei particular das forças diagonaes", Martius sugeriu a escrita da história do Brasil a partir do papel desempenhado por cada um dos três elementos que constituem o brasileiro (" a de côr de cobre ou americana, a branca ou caucasiana, e emfim a preta ou ethiopica "), assim como defendeu um estilo particular para tanto, obviamente voltado para o enaltecimento da monarquia lusitana: "d'aqui resulta que a obra, a qual não devia exceder a um só forte volume, deverá ser escripta em um estylo popular, posto que nobre. Deverá satisfazer não menos ao coração do que á intelligencia; por isso, não devia ser escripta em uma linguagem do [ ?] e empolada, nem sobrecarregada de erudicção ou de uma multidão de citações estereis. Evitará não menos ter o carater de uma chronica, do que de investigações historicas, seccas e puramente eruditas". MARTIUS, Carlos Frederico Ph de. Como se deve escrever a historia do Brasil. Dissertação offerecida ao Instituto Historico e Geographico do Brasil, pelo Dr. Carlos Frederico Ph. de Martius. Acompanhada de uma Bibliotheca Brasileira, ou lista das obras pertencentes á Historia do Brasil. In: RIHGB, T.VI, 1844 p.381 e ss.

\section{7}

"Os melhores materiaes para escrever a historia do Brasil (e a de outros lugares), são os monumentos e as inscripções abertas em laminas de pedra e metallicas; os diplomas legislativos, as cartas imperiaes ou regias, os regulamentos ou regimentos, resoluções, avisos, provisões e patentes. Termos de posse dos governadores, bispos, magistrados, officiaes municipaes, e das outras classes de empregados publicos, e as cartas de sesmarias das terras concedidas aos mais antigos povoadores. Um critico mui austero deve presidir ao exame d'estes monumentos; observar o talho da letra, a côr e o estado das tintas, confrontar as eras ou as cousas com pessoas, enfim desempenhar os deveres de bom paleógrapho e bom chronologo. Se os escriptores do Brasil tivessem praticado estas regras que são imprescreptiveis, e aconselhadas desde a mais alta antiguidade por aquelles que estão reputados mestres dos historiadores, não teriamos o desgosto de encontrar ficções em vez de realidades, e de ler mui desfigurados alguns dos mais bellos episodios dos fastos brasileiros". MATTOS, Raymundo José da Cunha. Dissertação acerca do systema de escrever a historia antiga e moderna do Imperio do Brazil. RIHGB, T.XXVI, 1863. p.121 e ss.
Os falsos Documentos, que no fim do Séc. XVI, e principio do XVII. se fabricarão da Hespanha, e mesmo em Portugal, enredarão de tal maneira a nossa Historia, que dous Séculos, e o trabalho de tantos Sábios, não tem bastado a reduzi-la á sua pureza. A ignorância augmentou o mal, produzindo-nos cópias inexactas, e a cada passo defeituosas, principalmente nas datas [...] Estes inconvenientes, que a experiência repetidas vezes me fez palpáveis, tendo excitado as minhas averiguações sobre diversos artigos históricos, e juridicos, tem dado occasiao a ordenar algumas Dissertações, que vou consecutivamente publicar; por me persuadir que dellas poderá resultar algum interesse á nossa Litteratura, que por mais de hum titulo tenho obrigação de promover, quanto a mim cabe. ${ }^{25}$

Como se percebe, a dissertação se mostra como um mecanismo de comprovação histórica, uma prática erudita de administração das provas que servirão, posteriormente, para a escrita de uma "história verídica". Algo sensivelmente distinto do significado que o termo terá em meados do século XIX, por exemplo, na sempre citada dissertação de Karl Friedrich Philipp von Martius, publicada originalmente na década de 1840 pela Revista do Instituto Histórico e Geográfico Brasileiro. No premiado texto do botânico bávaro, não se encontra qualquer elemento definidor do que se poderia entender como crítica erudita, isto é, um mecanismo de definição e administração das evidências históricas. 0 naturalista preocupou-se, por outro lado, em elencar temas possíveis para a história do Brasil, assim como teceu breves comentários a respeito do estilo desejado para tanto. ${ }^{26}$ Outro exemplo ainda pode ser mencionado, como é o caso da "Dissertação acerca do systema de escrever a historia antiga e moderna do Imperio do Brazil", escrita pelo marechal Raymundo José da Cunha Mattos. Embora o autor português tenha demandado o "escalpello da boa critica" para alguns documentos, além de recomendar "as melhores" fontes para a história do Brasil, seu texto ocupa-se na maior parte do tempo em avaliar trabalhos escritos sobre o tema, bem como aponta sugestões para sua periodização. ${ }^{27}$

Os dois trabalhos são voltados para a definição de certos princípios metódicos para a escrita da história no Brasil oitocentista, pelos quais os autores discorrem sobre alguns temas escolhidos sem que, por isso, se configure um caráter de disputa dentro do texto. 0 teor propositivo de ambos denota justamente uma sugestão em aberto onde seus leitores poderão por ventura acatá-la ou não. Mas de forma alguma há nos textos os sinais de uma disputa erudita. 0 século XVIII, nesse sentido, parece atribuir uma importante função crítica a este gênero discursivo, dotando-o de um significado particular para os procedimentos de pesquisa histórica, o qual permanecerá, como se vê, até alguns eruditos da primeira metade do século seguinte, quando sua dimensão de disputa parece começar a esmorecer.

\section{IV}

Tomemos alguns exemplos retirados das dissertações lidas pelos acadêmicos Luis de Siqueira da Gama e Gonçalo Soares de França. Na sua terceira dissertação sobre a história política, Siqueira da Gama escolhe um tema considerado por ele relevante para disputar: "havemos dissertar se os Índios do Brasil, antes de ser descoberto e conquistado pelos portuguêses, tinham, ou não política, viviam, ou não com algum exercício de civilidade". 
28

GAMA, Luis de Siqueira da. Dissertações altercadas, e resolutas, para melhor averiguação da verdade na história do Brasil. In: CASTELLO, José Aderaldo. 0 movimento academicista no Brasil, 1641-1820-22. Vol.1, T.5. São Paulo: Conselho Estadual da Cultura, 1969. p.30-32.
29

Ibidem. p.32-34.
Para tanto, o acadêmico Ocupado passa então a apresentar as duas partes da contenda. "Nessa intrincada disputa a parte negativa se prova manifestamente pelas razões seguintes", que são em número de três: em primeiro lugar, defende-se a impossibilidade de política entre os nativos americanos pelo fato de que, considerando a religião como base de todo e qualquer Estado, o fato dos indígenas serem desprovidos de religião comprova que são igualmente desprovidos de política. "Os Índios primeiros habitadores do Brasil não conheciam fé, não professavam religião, não adoravam a Deus, eram bárbaros, eram feros, eram insociáveis; e tanto que até parece que em sinal da sua barbaridade Ihes negou o autor da natureza as letras $F, L, R$ ". A segunda razão é dada pelo fato de que toda política se manifesta como faculdade civil; não tendo civilidade em seus costumes, os indios também não têm política:

referem os historiadores tratando desta formosa, e Grande parte do mundo , que se os nacionais eram bárbaros, eram feros, eram insociáveis; eram insociáveis porque viviam dispersos pelas brenhas, e vagavam como reses às manadas; eram feros porque o prato do seu maior aprêço era o de carne humana, que comiam vorazmente com maior gôsto: eram bárbaros, porque sem honestidade, e sem vergonha andavam de todo nus, e só as mulheres cobriam com um ramo verde 0 mais imodesto, de que tanto se peja a pudícia dos racionais.

Enfim, como terceira razão negativa apresentada contra a existência de política ente os grupos americanos, a dimensão divina da política: "sociedade política deduz a sua origem de Deus, e da natureza humana [...] e nesta conformidade, verossimil é, que sendo tão brutos, que não pareciam homens não teriam entre si sociedade". 28

Como contraponto, Siqueira da Gama indica a parte contrária, "a parte afirmativa [onde se] propugnam os seguintes fundamentos": apesar da aparente rudeza, os indios não eram brutos, chegando, inclusive, a organizar sua vida social de acordo com demandas produtivas. "Cuidando os Índios do Brasil da sua comodidade em melhor passagem, segundo as estações do ano, fertilidade, e abundância dos sítios; é sem controvérsia que se governavam pelos ditames da política, e que não eram tão bárbaros, que parecessem irracionais". Além disso, se um dos elementos mais evidentes da existência da política entre grupos sociais é a comunhão entre seus membros, a existência de relações matrimoniais entre os indios é prova contundente para quem defende a dimensão política de sua existência. Por fim, última razão afirmativa, os índios eram passiveis de catequização e, dessa maneira, não eram feras irracionais desprovidos de qualquer sentido social para sua existência. Enquanto seres racionais, portanto, eram também seres políticos. Quanto a isso, o próprio acadêmico atesta o valor da assertiva: "é coisa que vemos, e como vemos, não necessita de outra alguma confirmação".29

Apresentadas as duas posições, cabe àquele que profere a dissertação elaborar seu juizo crítico, asseverando o argumento que the parece mais adequado para figurar em uma história. Com essa intenção, Siqueira da Gama opta por uma solução sintética, um meio termo entre ambas as posturas. 0 resultado é visivelmente retórico: o autor considera dois significados principais para a idéia de política: "política rigorosa, e estreitamente considerada", e "politica considerada mais larga". A primeira diz respeito ao âmbito da administração e da organização burocrática do Estado, isto é, política como faculdade civil; a outra encontra seu pleno 
30

GAMA, Luis de Siqueira da. Dissertações altercadas, e resolutas, para melhor averiguação da verdade na história do Brasil. In: CASTELLO, José Aderaldo. 0 movimento academicista no Brasil, 1641-1820-22. Vol.1, T.5. São Paulo: Conselho Estadual da Cultura, 1969. p.35.

31

FRANÇA, Gonçalo Soares de. Dissertações da história eclesiástica do Brasil. In: CASTELLO, José Aderaldo. Op.Cit. p.234.
32

Ibidem. p.254.

33

Ibidem. p.249-255. sentido na dimensão comunitária da vida em sociedade. Com isso, a resposta mais plausivel segundo o acadêmico é considerar que os indigenas dispõem de política apenas em seu primeiro significado: "dizemos, que os primeiros habitadores do Brasil, já no tempo do nosso descobrimento tinham e têm dêste ou daquele modo, esta tal sociedade, e comunhão politica". Por sua vez, se apenas for considerara a política estrita, "é sem a menor controvérsia, não usarem os tais Índios bárbaros de política alguma, rigorosamente considerada enquanto faculdade civil". 30

De sua parte, o padre Soares de França, realiza tarefa similar nas dissertações sobre a história eclesiástica no Brasil, embora um tanto mais sofisticada do ponto de vista da erudição histórica. A tal ponto que o acadêmico se mostra seguro em criticar um eminente historiador português, justamente em termos de prática documental. 0 assunto trata da história das navegações portuguesas e o religioso se mostra desconfiado, com base em um manuscrito apenas mencionado, diante da prática historiográfica de João de Barros.

Reconheço todavia muito bem, que a autoridade de João de Barros entre os nossos é tanta, que não sofre ser impugnada com uma relação manuscrita; e suposto que a esta pudéramos defender com muitos, e mui próprios exemplos, de nenhum quero usar, mas só concluir que bem, ponderada a sentença do nosso historiador, parece mais conjectura alheia, que opinião própria, pois a indiferença com que fala dá lugar a que a relação e a década possam ser verdadeiras. ${ }^{31}$

Ou seja, o fundamento da crítica reside na forma como as evidências são administradas: de um lado, o amparo em fontes manuscritas, de outro, a informação "por ouvir dizer", pautada em opinião de terceiros. Na sua dissertação histórica, portanto, o valor documental das assertivas encontra pleno significado.

Discorrendo sobre quem teriam sido os primeiros povoadores do Brasil, quando e como eles aqui chegaram (dissertação terceira), o autor adverte logo de início: "hoje forçosamente havemos de questionar, e suposto, que sem faltar aos preceitos da Retórica campearão mais as normas da dialética, porque temos de auferir e impugnar as diversas opiniões que há acêrca dos primeiros povoadores do Brasil, para então estabelecer a nossa resolução". 0 religioso se dispõe a apresentar, em primeiro lugar, as versões indigenas sobre o fato, logo em seguida desqualificando-as como "patranhas" fabulosas, opondo a elas a "verdade infalivel do texto sagrado". Depois, apresenta versões de diversos autores, algumas delas situando os indigenas como fugitivos, tal qual Enéias, da guerra de Tróia; outras sugerindo que os nativos foram "trazidos de Anjos pelos cabelos". Soares de França, por fim, indica aquela que considera a versão mais verossímil, pela qual os índios chegaram ao território americano pelo Estreito de Antão, atual estreito de Behring. ${ }^{32}$ Nas suas palavras:

\footnotetext{
Mas, ou fôssem uns, ou fôsse outro, a opinião mais provável, ou ao menos a que eu mais aprovo é, que êstes descendentes de Noé da referida parte pelo mencionado estreito vieram a ser os primeiros povoadores da nova Espanha, e consequentemente do Brasil, porque em pequenas balsas, canoas, ou jangadas, e ainda com sofriveis nados, em que são incansáveis os Índios, em tão breve distância, não só os homens poderiam pôr em efeito o seu desejo, mas ainda os animais em execução o seu intento; e transferidos daquela a esta parte do mundo, com facilidade se foram difundindo, e espalhando pelo mais continente da América. 33
} 
34

Sobre a "operação historiográfica" de Heródoto, ver HARTOG, François. 0 espelho de Heródoto. Ensaio sobre a representação do outro. Belo Horizonte: Ed. da UFMG, 1999.

35

Ver GINZBURG, Carlo. Sobre Aristóteles e a história, mais uma vez. In: Relações de força. História, retórica, prova. São Paulo: Companhia das Letras, 2002

36

FRANÇA, Gonçalo Soares de. Dissertações da história eclesiástica do Brasil. In: CASTELLO, José Aderaldo. 0 movimento academicista no Brasil, 1641-1820-22, Vol.1, T.5. São Paulo: Conselho Estadual da Cultura, 1969. p.267.

37

Ibidem. p.227.

38

MOTA, Isabel Ferreira da. A academia Real da História. Os intelectuais, o poder cultural e o poder monárquico no século XVIII. Coimbra: Minerva, 2003. p.63.

39

KANTOR, Iris. Esquecidos e Renascidos. Historiografia acadêmica luso-brasileira (17241759). São Paulo: Hucitec; Salvador: Centro de Estudos Baianos/UFBA, 2004. p.193.
0 interesse para este trabalho está na maneira pela qual o acadêmico sustenta seu argumento. Não apenas no caso da origem dos indigenas americanos, mas no conjunto das suas reflexões, ele indica, sobretudo, três fatores de prova principais: textos, seja na forma de manuscritos ou impressos; experiência, no sentido prático que assume a idéia de investigação ou historíe desde Heródoto; ${ }^{34}$ e raciocínio lógico, modelo comprobatório que encontra lugar desde os silogismos da Retórica aristotélica. ${ }^{35}$ No caso deste, um exemplo é esclarecedor. Defendendo a vinda de São Tomé, Soares de França argumenta da seguinte maneira: "se nas três partes do mundo pregaram os mais Apóstolos como sabemos, porque nesta quarta parte não pregaria São Tomé?", complementando ainda indagando "que maior razão pois se dá para que pregasse êste Apóstolo na Ásia, e não evangelizasse na América; se os da América são gentios, gentios eram os da Ásia". 36 No caso da prova por experiência, 0 exemplo dado são as explorações in loco feitas no já referido Estreito de Antão, que asseguram a possibilidade do trajeto entre o continente asiático e o americano. Por fim, o autor arrola lista sobre documentos impressos e manuscritos aos quais teve acesso para elaborar seu trabalho. "Para erigi-la [a dissertação] unirei os materiais, que se acham dispersos por alguns Livros impressos, e manuscritos, a que não dou menos crédito que aos primeiros, por serem alfaias, que como morgado herdei dos antigos Avós, que na guerra, e na paz ocuparam os primeiros lugares desta República". ${ }^{37}$ Ou seja, as disputas contidas nas dissertações de história eclesiástica são amparadas por um forte aparato comprobatório que, posteriormente, já com a disputa resolvida, legitimarão a escrita historiográfica.

\section{$\mathrm{V}$}

Considerando, por fim, algumas das modalidades de discursos utilizados pelos historiadores portugueses na primeira metade do século XVIII, é possivel perceber o lugar das dissertações dentro do conjunto dos procedimentos de que se valiam tais autores. Isabel Ferreira da Mota, em seu importante estudo sobre a Academia Real da História de Portugal, informa que na instituição fazia-se, como se continuará fazendo ao longo do século XIX, uma distinção clara entre História e Memórias. Nas suas palavras, "nas memórias, cada uma das partes pode suster-se por si; a história é uma narração perpétua e constante dos feitos".38 Iris Kantor discorre igualmente sobre o tema, considerando que as memórias para os autores brasílicos do século XVIII, equivaleriam àquilo que contemporaneamente chamamos de "instrumentos de pesquisa". Kantor indica que "as memórias eram essencialmente compilação documental ou mesmo resumos informativos: constituiam arrolamentos ou 'aparatos críticos' em formato de catálogos de autoridades (bispos e governadores), mapas de rendimentos (contratos, dízimos e soldos), tabuadas cronológicas, cartas geográficas, desenhos de vilas e edificações, repertórios genealógicos, legislativos e bibliográficos". 39

O Systema da Historia Ecclesiástica, \& Secular de Portugal, que ha de escrever Academia Real da História Portuguesa, espécie de programa metodológico para os acadêmicos, assevera aos membros que "naõ se faraõ dissertações, ou notas separadas das Memorias no fim dos Livros, e Capitulos, porque no mesmo contexto se haõ de tratar as duvidas, com a liberdade que permite este genero de Historia, sem obrigar a quem 
Systema da Historia Ecclesiástica, \&t Secular de Portugal, que ha de escrever Academia Real da História Portuguesa. In: In: Collecçam dos documentos, estatutos, e memorias da Academia Real da Historia Portugueza, que neste anno de 1721, se compuzerão, e se imprimirão por ordem dos seus censores, dedicada a El Rey Nosso Senhor, Seu Augustissimo Protector, e ordenada pelo Conde de Villamayor, secretario da mesma Academia. Lisboa Occidental: na Oficina de Pascoal da Sylva, impressor de S. Magestade Real. MDCCXXI [1721].

\section{1}

LEAL, Manuel Pereira da Silva. Memorias para a historia ecclesiastica do bispado da Guarda. Parte primeira. Lisboa Ocidental: Officina de Joseph Antonio da Sylva, 1729; citado em MOTA, Isabel Ferreira da. A academia Real da História. Os intelectuais, o poder cultural e o poder monárquico no século XVIII. Coimbra: Minerva, 2003. p.42. a lê a que và a outra parte a resolução das questoens". 40 Isabel Mota menciona ainda a obra de Manuel Pereira da Silva Leal, sobre a história eclesiástica do bispado da Guarda, de 1729, em que o autor considera que "muito mais difícil e laborioso he o emprego de juntar, discutir, examinar, escolher, e pôr em ordem Memorias, que hão de depois servir para se escrever por ellas a Historia, já livre das controversias, e disputas, que a memoria decidio com trabalho, e paciencia". ${ }^{41}$ Convém salientar a distinção formal estabelecida pelo autor nesta passagem, que permite diferenciar o primeiro termo pluralizado e com inicial maiúscula ("Memorias"), do segundo termo, singular e iniciando com minúscula ("memoria"). Ou seja, naquele caso, o termo refere-se a um gênero discursivo preciso, enquanto que neste, à arte intelectual (ars memoriae) que possibilita a lembrança. Por conseguinte, é possivel indicar duas etapas precisas e distintas para o trabalho historiográfico: a elaboração laboriosa das memórias e a escrita propriamente da história. Fato importante de se notar é que esta apenas é produzida quando sobre aquelas não mais pairam controvérsias ou desentendimentos, isto é, quando seus conteúdos específicos já foram disputados, em muitos casos pela forma dissertativa.

Assim, as dissertações acadêmicas dos Esquecidos, ecoando uma tradição que remonta à própria Academia Real da História Portuguesa, trazem a particularidade, pelo menos para o contexto brasílico, de se constituirem como elementos próprios de uma disputa discursiva em que duas partes ou proposições são colocadas em paralelo para que, do confronto instaurado entre elas, sobressaia o enunciado tido pelo autor da dissertação como o mais adequado ou mesmo como o mais condizente com a verdade histórica dos fatos. Com isso, elas se constituem como etapas fundamentais para a escrita da história propriamente dita. Entre as memórias e a "História", a dissertação aparece, portanto, como uma modalidade de disputa pelo passado, situada no espaço impreciso, mas evidente, entre as letras e as armas. 